\title{
Inorganic Agents Modified Epoxy Eesin
}

\section{CLAUDIA-MIHAELA GOROVEI ${ }^{1}$, ALINA-MIHAELA CEOROMILA ${ }^{2}$, VASILE BRIA ${ }^{1,2}$, ADRIAN CIRCIUMARU ${ }^{1,2 *}$, IULIAN-GABRIEL BIRSAN ${ }^{1,2}$}

${ }^{1}$ Research and Development Center for Thermoset Matrix Composites, Dunărea de Jos University of Galati, 111 Domneasca Str., 800008, Galati, Romania

${ }^{2}$ Cross-border Faculty, Dunărea de Jos University of Galati, $111^{\text {th }}$ Domneasca Str., 800008, Galati, Romania

\begin{abstract}
An additive is a substance, which when incorporated into polymer materials might lead at improvements on the electrical, thermal or mechanical properties of finished products in dependence of their applications, such as automotive, electronics, packaging and consumer goods. This study is based on the idea of using inorganic agents to change the basic properties of an epoxy resin. The well-known plasticizer 1-methyl-2-pyrrolidinone (NMP) was used to solve the inorganic agents and the mixture of obtained solutions was added, in certain amounts, into the epoxy resin prior the hardener of the epoxy system. The idea is to test the hypothesis offorming of ceramic nanostructures into the polymer structure based on local chemical interaction between solved inorganic compounds in certain conditions. The present paper concerns with the effect of changes on the mechanical properties of the epoxy resin.
\end{abstract}

Keywords: epoxy resins, NMP, PVP, inorganic salts, elastic modulus

\section{Introduction}

Epoxy resins are oligomers containing ethylene oxide groups, which are hardened by reacting of epoxy groups with a suitable curing agent. Epoxy polymers give high strength, low shrinkage, good adhesion to various substrates, excellent electrical insulation, high chemical resistance, low toxicity and low cost. The three basic constituents of an epoxy system are: resin, curing agent and modifier [1-10].

The fillers can be used for improvement of the composites properties such as general durability, stiffness and strength, impact repetition, thermal resistance, bending and wear resistance, acoustic insulation, etc. A large range of fillers are used for expanding the range of plastics with improved mechanical and thermal properties, chemical and corrosion resistance, flame retardant, electrical conductivity [11-17].

Polyvinylpyrrolidone (PVP) is a non-ionic linear polymer and it is compatible with a variety of resins and electrolytes. It is a physiologically inert material, which forms hard, transparent, glossy, oxygenpermeable, adhesive and cohesive films. It has a hygroscopic nature. It is soluble in water and other polar solvents, insoluble in esters, ethers, ketones and hydrocarbons [18, 19]. PVP has a high degree of compatibility with natural and synthetic resins, most inorganic salts and many other chemical compounds. This is a versatile ingredient used in the pharmaceutical, cosmetic, industrial, biomedical applications as a plasma substitute, pharmaceutical tablet binders, wound dressings and disinfectant hydrogels. It can be dissolved in hydrocarbons to prepare dilute solutions using diverse co-solvents such as nonylphenol, butanol or N-methyl-2-pyrrolidone [20-22]. N-methyl-2-pyrrolidone (NMP) is a colourless solvent with a boiling point of $202^{\circ} \mathrm{C}$ and low viscosity. NMP has a low toxicity, it is a polar liquid. It is an useful solvent in all scientific fields, mainly, due to its advantages in terms of stability at ambient temperature, low volatility, low flammability and industrial use in the field of petrochemical processing, surface coating and plastics [23]. NMP is completely miscible with water at all temperatures and it has high polarity. It can dissolve salts and it is, also, soluble with most organic solvents. It is well known that amides (NMP) interacting with water or alcohols by dipole-dipole interactions form some hydrogen or hetero-related complexes [24-27].

*email: adrian.circiumaru@ugal.ro 
The applications of NMP solvent include petrochemical processes (acetylene, butadiene, lubricating oil), the synthesis of the polymers (polyethersulfones, polyimides, polyaramids), solvent for resins, paints, adhesives, cleaning agents and the obtaining of lithium-ion batteries and graphene [28].

S. E. Jasim et al. [29] obtained YBCO superconducting nanoparticles supplemented with polyvinylpyrrolidone (PVP) by electrochemical electrospinning method. After treatment and thermal testing, they have obtained a typical diameter of nanoparticles between 20 and $50 \mathrm{~nm}$. The surface of the YBCO nanoparticle was not affected by calcination. Lu et al. [30] achieved PVP/ $\mathrm{Ag}_{2} \mathrm{~S}$ nanoparticles using silver nitrate $\left(\mathrm{AgNO}_{3}\right)$, ethanol and polyvinylpyrrolidone. The researchers observed by Fourier-transform infrared spectroscopy (FTIR) that PVP powders play an important role in the dispersion of $\mathrm{Ag}_{2} \mathrm{~S}$ nanoparticles.

V. Rodaev et al. [31] used the electrospinning method to obtain composite fibres. It was used $\mathrm{ZrOC}_{12}$, $\mathrm{Al}\left(\mathrm{NO}_{3}\right)_{3}, \mathrm{ZrO}_{2}, \mathrm{Al}_{2} \mathrm{O}_{3}$ and PVP powders. They found that the fibre thickness was diminished after thermal treatment by filament shrinkage, which led to the thermal decomposition of the oxides and polyvinylpyrrolidone. Guo-Xun Sun et al. [32] achieved zirconium-based nanofibres by using of $\mathrm{Y}\left(\mathrm{NO}_{3}\right)_{3},\left(\mathrm{CH}_{3} \mathrm{O}_{7} \mathrm{Zr}_{2}\right),\left(\mathrm{CH}_{3} \mathrm{COOH}\right)$ and PVP powders. Due to TG-DTA curves it was observed that from $240^{\circ} \mathrm{C}$ to $450^{\circ} \mathrm{C}$, weight loss of composite fibers was approximately $19 \%$ following the decomposition and carbonization of PVP and acetic acid.

The present investigation assumes that it is possible to obtain ceramic nano-structures inside a polymer volume based of a mechanism similar to citric gels method. That is why the used inorganic agents were $\mathrm{Cu}\left(\mathrm{NO}_{3}\right)_{2}, \mathrm{Y}\left(\mathrm{NO}_{3}\right)_{3}$ and $\mathrm{Ba}\left(\mathrm{NO}_{3}\right)_{2}$, on one hand and $\mathrm{Ag}\left(\mathrm{NO}_{3}\right), \mathrm{ZrO}\left(\mathrm{NO}_{3}\right)_{2}, \mathrm{Ba}\left(\mathrm{NO}_{3}\right)_{2}$ on another hand.

It is well-known the fact that concept of nano-structuration of polymers means basically to add some nano-dimensional particles into the polymer volume aiming to determine some changes in polymer behaviour. The present study is about an investigation on obtaining ceramic nano-structures directly into the epoxy resin volume considering the resin as a gel (such as in citrate gel method). At the Research and Development Centre for Thermoset Matrix Composites (CCDCOMT) there were purposed other studies regarding the electrical conductivity of epoxy resins and ways in which this could be changed by using various inorganic agents (sodium dichromate, potassium dichromate) and the results were encouraging. This new approach, based on CCDCOMT knowledge, was determined by the existence of YBCO - a well-known material with special electrical properties and aimed to test the hypothesis of obtaining the nano-dimensional compounds by ensuring locally developed chemical reactions between precursors (inorganic salts).

The success of such an approach might be attractive for researchers and engineers because it would allow energy savings (avoiding the prior nano-dimensional structures preparation), and also it would lead to a uniform dispersion of nano-structures inside the polymer (avoiding the often reported aggregation of nano-dimensional particles when they are placed into the liquid phase). The formed materials could be used in designing multifunctional materials or, due to their special properties, as valuable materials in optoelectronics.

\section{Materials and methods}

The epoxy system RE4020 - DE4020 was used to form the polymer based materials modified with $\mathrm{Cu}\left(\mathrm{NO}_{3}\right)_{2}, \mathrm{Y}\left(\mathrm{NO}_{3}\right)_{3}, \mathrm{Ag}\left(\mathrm{NO}_{3}\right), \mathrm{ZrO}\left(\mathrm{NO}_{3}\right)_{2}, \mathrm{Ba}\left(\mathrm{NO}_{3}\right)_{2}$ all of them provided by Sigma-Aldrich, Polyvinylpyrrolidone (PVP) and 1-methyl-2-pyrrolidinone (NMP) (also from Sigma-Aldrich). Polypropylene tubes with $8 \mathrm{~mm}$ diameter and $220 \mathrm{~mm}$ length were used as moulds. The reference sample was made of EPIPHEN epoxy-type system RE4020 (resin) - DE4020 (hardener) with 100:30 ratio, mixed mechanically until the materials were homogenized. The gelation time was approximately 45 $\min$.

For the modified samples firstly the inorganic salts, calculated on a stoichiometric basis, were separately solved into $50 \mathrm{~mL}$ of NMP as described in Table 1 and the $5 \mathrm{~g}$ of PVP were added to stabilize each solution. The solutions were prepared on magnetic stirrers at $250 \mathrm{rot} / \mathrm{min}$ and $70^{\circ} \mathrm{C}$ during a period 
of 10 days. It is known the fact that the properties of a composite are dependent on matrix properties, reinforcement or filler or modifying agent properties but also on the forming technique. This is the reason for the final materials were prepared on two ways. First one was to add equal amounts of solutions of inorganic salts into the required quantity of resin and the second by adding the same quantity of each solution but each one in one third of the required quantity of resin. The obtained mixtures were stirred, on the same conditions, for $24 \mathrm{~h}$. The three partial mixtures were joined and the stirring was continued for another $24 \mathrm{~h}$ for both types of samples. Table 2 and Table 3 show the amounts of components used to get the modified materials.

Table 1. Amounts of additives and solvent used to form polymer blends

\begin{tabular}{|c|c|c|c|c|c|c|}
\hline $\mathrm{NMP}$ & $\mathrm{Cu}\left(\mathrm{NO}_{3}\right)_{2}$ & $\mathrm{Y}\left(\mathrm{NO}_{3}\right)_{3}$ & $\mathrm{Ag}\left(\mathrm{NO}_{3}\right)$ & $\mathrm{Zr}\left(\mathrm{NO}_{3}\right)_{4}$ & $\mathrm{Ba}\left(\mathrm{NO}_{3}\right)_{2}$ & $\mathrm{PVP}$ \\
\hline $50 \mathrm{ml}$ & $30 \mathrm{mmol}$ & $10 \mathrm{mmol}$ & - & - & $20 \mathrm{mmol}$ & $5 \mathrm{~g}$ \\
& - & - & $30 \mathrm{mmol}$ & $20 \mathrm{mmol}$ & $20 \mathrm{mmol}$ & $5 \mathrm{~g}$ \\
\hline
\end{tabular}

For each of the two combinations of inorganic salts two concentrations were used to obtain the prepolymer mixtures. After the adding of necessary amount of epoxy hardener the blends were mixed for 5 min and then the mixture was poured into the moulds as described above.

The materials were tested from mechanical point of view by means of traction loading using an Instron machine with custom made grips for cylindrical samples. The machine software application returns (by request) some parameters of interest at critical moments of samples evolution namely at elasticity limit, at maxim loading and at break.

In order to investigate the validity of enounced hypothesis (the one of nanostructures forming) SEM analysis was done and we present the results of this analysis. However, the SEM analysis is a limited one since it is performed on some delimited areas in the fracture zone (the SEM analysis was done inside a fracture surface that had been obtained after the sample cooling in liquid nitrogen). As references for the mechanical properties we used two materials, denoted as R1 and R2, what formation was presented before in [32] were they are denoted as M1 and M2.

\section{Results and discussions}

Since the composites properties are strongly dependent on the forming conditions the analysis of materials had been performed for the two ways of components mixtures. Because of the presence of Y, $\mathrm{Ba}$ and $\mathrm{Cu}$ in one type of materials and $\mathrm{Zr}, \mathrm{Ba}$ and $\mathrm{Ag}$ in the other type of materials the denominations of them are made as YBC and ZBA. As presented above one way to mix the components was to put certain volumes of salts solutions into the main component of epoxy system and these materials are denoted with $(3 \mathrm{~g})$ or $(6 \mathrm{~g})$ - with the $\mathrm{g}$ from generally. The other materials were obtained by firstly disperse and homogenize a certain volume of the salt solution in one third of computed quantity of epoxy main component and then to mix the three mixtures and these type of materials will be denoted as (s) with the $\mathrm{s}$ from separate technique or $(\mathrm{g})$ - with the $\mathrm{g}$ from global technique (according to the data in Table 1, for $\mathrm{g}$, and Table 2 for $\mathrm{s}$.

Table 2. Materials used to globally form the polymer blend

\begin{tabular}{|c|c|c|c|c|c|c|c|}
\hline $\begin{array}{c}\text { Sample } \\
\text { code }\end{array}$ & $\begin{array}{c}\text { Epoxy } \\
\mathrm{RE4020} \\
{[\mathrm{mL}]}\end{array}$ & $\begin{array}{c}\text { Hardener } \\
\mathrm{DE} 4020 \\
{[\mathrm{~mL}]}\end{array}$ & $\begin{array}{c}\mathrm{Cu}\left(\mathrm{NO}_{3}\right)_{2} \\
\text { solution } \\
{[\mathrm{mL}]}\end{array}$ & $\begin{array}{c}\mathrm{Y}\left(\mathrm{NO}_{3}\right)_{3} \text { solu } \\
\text { tion } \\
{[\mathrm{mL}]}\end{array}$ & $\begin{array}{c}\mathrm{Ag}\left(\mathrm{NO}_{3}\right) \\
\text { solution } \\
{[\mathrm{mL}]}\end{array}$ & $\begin{array}{c}\mathrm{Zr}\left(\mathrm{NO}_{3}\right)_{4} \\
\text { solution } \\
{[\mathrm{mL}]}\end{array}$ & $\begin{array}{c}\mathrm{Ba}\left(\mathrm{NO}_{3}\right)_{2} \\
\text { solution } \\
{[\mathrm{mL}]}\end{array}$ \\
\hline $\mathrm{C} 1$ & 131.53 & 39.47 & 3 & 3 & - & - & 3 \\
\hline $\mathrm{C} 2$ & 131.53 & 39.47 & - & - & 3 & 3 & 3 \\
\hline $\mathrm{C} 3$ & 124.84 & 37.16 & 6 & 6 & - & - & 6 \\
\hline $\mathrm{C} 4$ & 124.84 & 37.16 & - & - & 6 & 6 & 6 \\
\hline
\end{tabular}


Table 3. Materials used to separately form the polymer blend

\begin{tabular}{|c|c|c|c|c|c|c|c|}
\hline $\begin{array}{c}\text { Sample } \\
\text { code }\end{array}$ & $\begin{array}{c}\text { Epoxy } \\
\text { RE4020 } \\
{[\mathbf{m L}]}\end{array}$ & $\begin{array}{c}\text { Hardener } \\
\text { DE4020 }[\mathbf{m L}]\end{array}$ & $\begin{array}{c}\mathrm{Cu}\left(\mathrm{NO}_{3}\right)_{2} \\
+\mathrm{PVP} \\
{[\mathbf{m L}]}\end{array}$ & $\begin{array}{c}\mathrm{Y}\left(\mathrm{NO}_{3}\right)_{3}+\mathrm{P} \\
\mathrm{VP} \\
{[\mathbf{m L}]}\end{array}$ & $\begin{array}{c}\mathrm{Ag}\left(\mathrm{NO}_{3}\right) \\
+\mathrm{PVP} \\
{[\mathbf{m L}]}\end{array}$ & $\begin{array}{c}\mathrm{Zr}\left(\mathrm{NO}_{3}\right)_{4}+\mathrm{P} \\
\mathrm{VP} \\
{[\mathbf{m L}]}\end{array}$ & $\begin{array}{c}\mathrm{Ba}\left(\mathrm{NO}_{3}\right)_{2}+\mathrm{PV} \\
\mathbf{P} \\
{[\mathbf{m L}]}\end{array}$ \\
\hline $\mathrm{Cnnnyyyy}$ C1 & 43.86 & \multirow{2}{*}{39.47} & 3 & 3 & - & - & 3 \\
\hline $\mathrm{C} 2$ & 43.86 & & & & 3 & 3 & 3 \\
\hline $\mathrm{C} 3$ & 41.61 & \multirow{2}{*}{41.61} & 6 & 6 & - & - & 6 \\
\hline $\mathrm{C} 4$ & 41.61 & & & & 6 & 6 & 6 \\
\hline
\end{tabular}

Mechanical tests have been done on three samples of each material and the results are showed in Figure 1, for globally formed materials and in Figure 2, for separately formed materials. It is easily to notice that the separate strategy leads to lowered responses of materials comparing with the responses of global strategy, at the same amount of inorganic solution in the polymer. Also one may notice that the $\mathrm{C} 1$ and $\mathrm{C} 3$ materials respond more favourable than the $\mathrm{C} 2$ and $\mathrm{C} 4$ materials inside the both strategies. If the first behaviour might be attributed to the higher concentration of NMP, in the case of the second observation the mentioned behaviour has to be associated with the presence of inorganic salts - of Yttrium and Copper (for C1 and C3) and Zirconium and Silver (for C2 and C4).

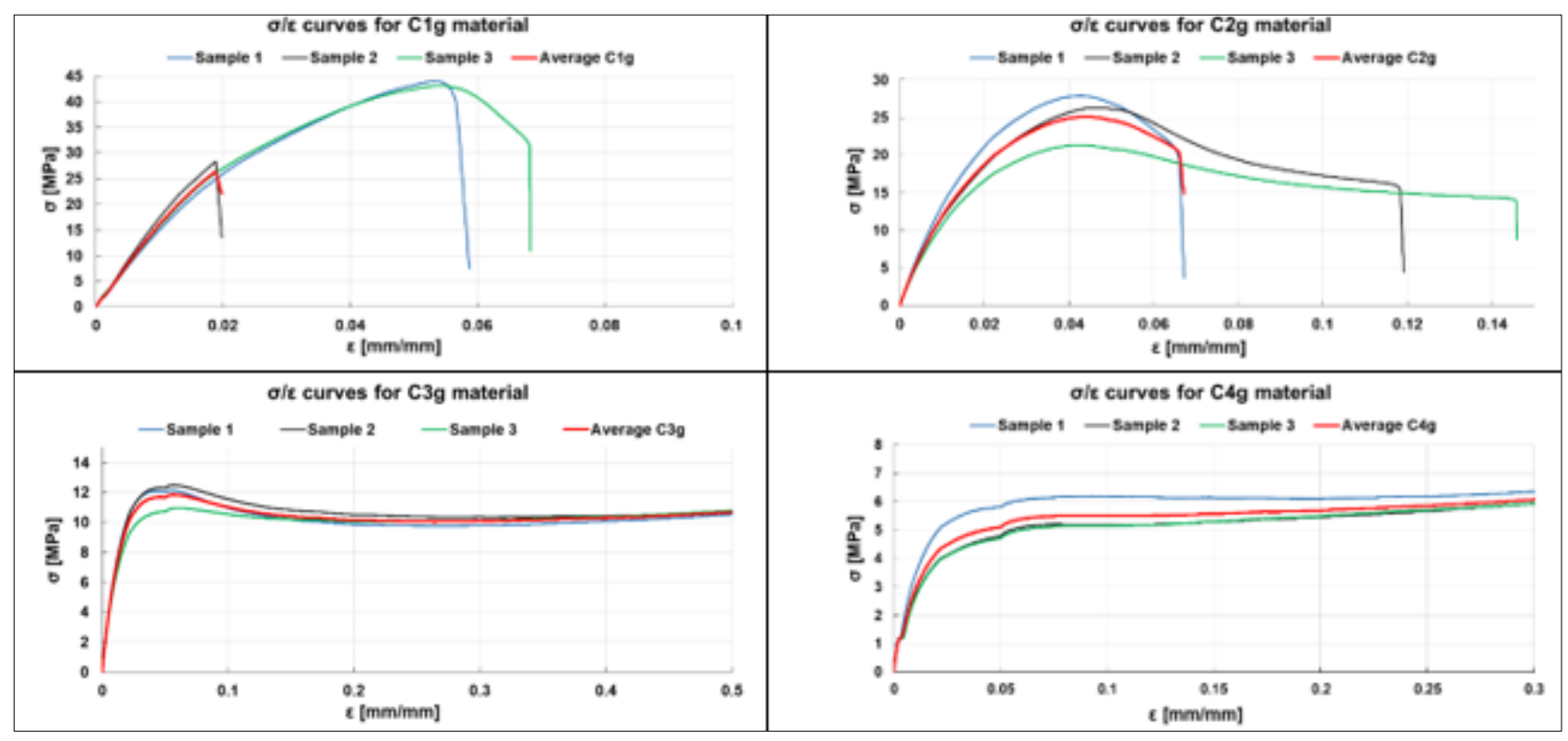

Figure 1. Stress/strain curves for globally formed materials

Also, analysing the named figures one may notice that in the case of $\mathrm{C} 1$ and $\mathrm{C} 3$ materials the samples behaviour is more compact meaning the curves are not dispersed denoting stable materials while the curves corresponding to various samples of $\mathrm{C} 2$ and $\mathrm{C} 4$ materials show a more divers behaviour. It is possible to connect this stability with the structure of materials (excepting the presence of PVP/NMP solution) if the hypothesis of eventual local chemical reactions is correct. In this case, the response of separately formed materials is lowered because they are less reliable to lead to chemical reactions do the fact that each salt component is surrounded by epoxy molecules prior the amalgamation of the partial solutions. In the case of globally formed materials, the partial solutions are amalgamated together prior their mixture with the epoxy resin and even there are some PVP molecules the probability of chemical interaction is higher.

It is well-known the fact that there are many complex oxides of $\mathrm{Y}_{\mathrm{x}} \mathrm{Ba}_{\mathrm{y}} \mathrm{Cu}_{\mathrm{z}} \mathrm{O}_{\mathrm{t}}$ one of them having outstanding electrical properties and perhaps inside the $\mathrm{C} 1$ and $\mathrm{C} 3$ materials some of these complex oxides had been formed leading to the higher stability of materials wile, in the case of the other analysed salts, formation of complex oxides did not occurred. 


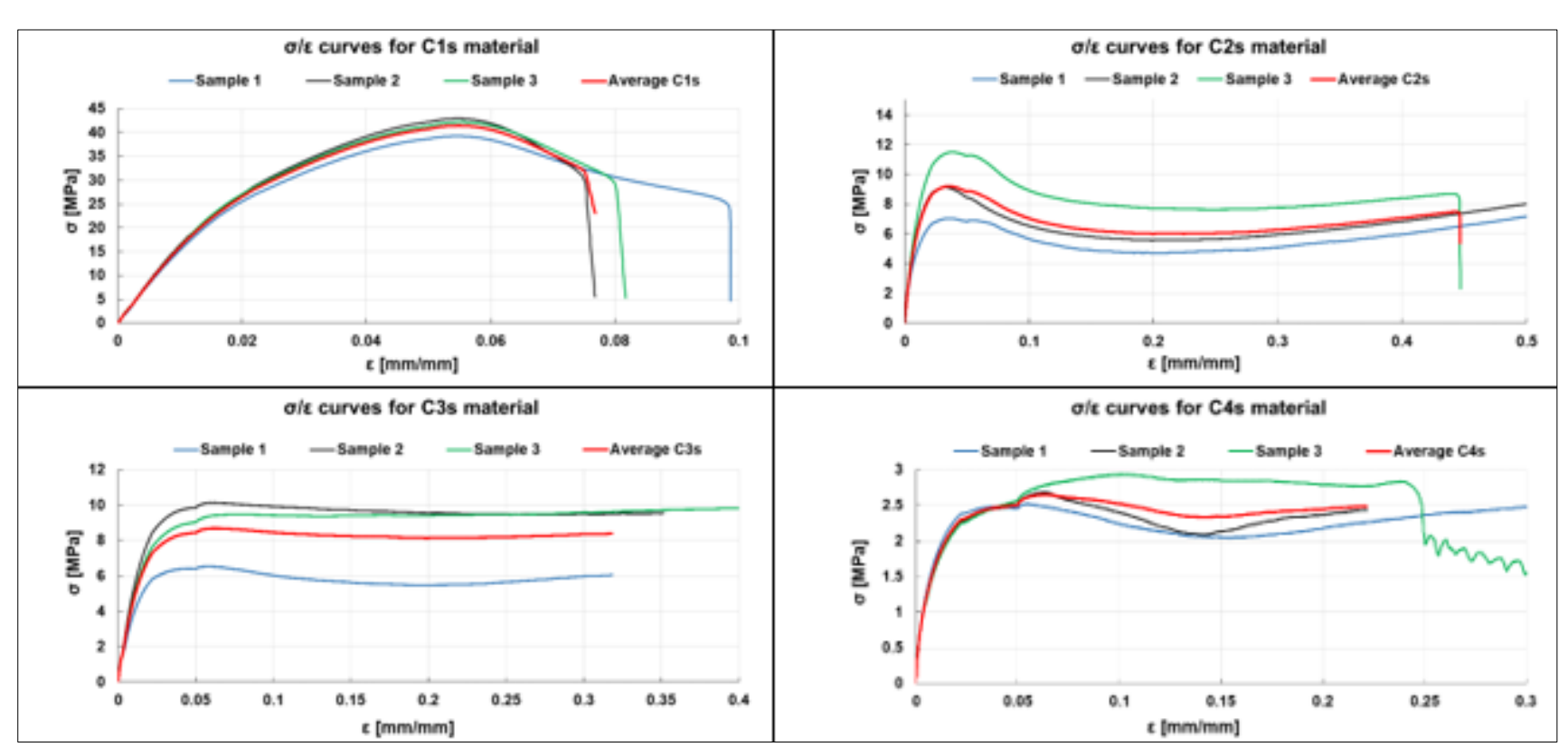

Figure 2. Stress/strain curves for separately formed materials

In Figure 3 an analysis between averaged responses of reference materials (R1 and R2) and formed materials averaged responses is presented. The R1 material is a material formed with 5\%(vr) PVP/NMP solution such as C1 and C2 while R2 is formed with 10\%(vr) PVP/NMP solution in the same epoxy resin. It is obvious that the $\mathrm{R} 1$ and $\mathrm{R} 2$ responses (highest values of stress) are superior to the ones of studied materials and that is due to the inorganic salts presence. In both cases, the responses of inorganic salts materials are lower than the ones of PVP/NMP modified materials and, also in both cases, the responses of materials with Yttrium, Barium and Copper salts are superior to the ones of Zirconium, Barium and, Silver salts.
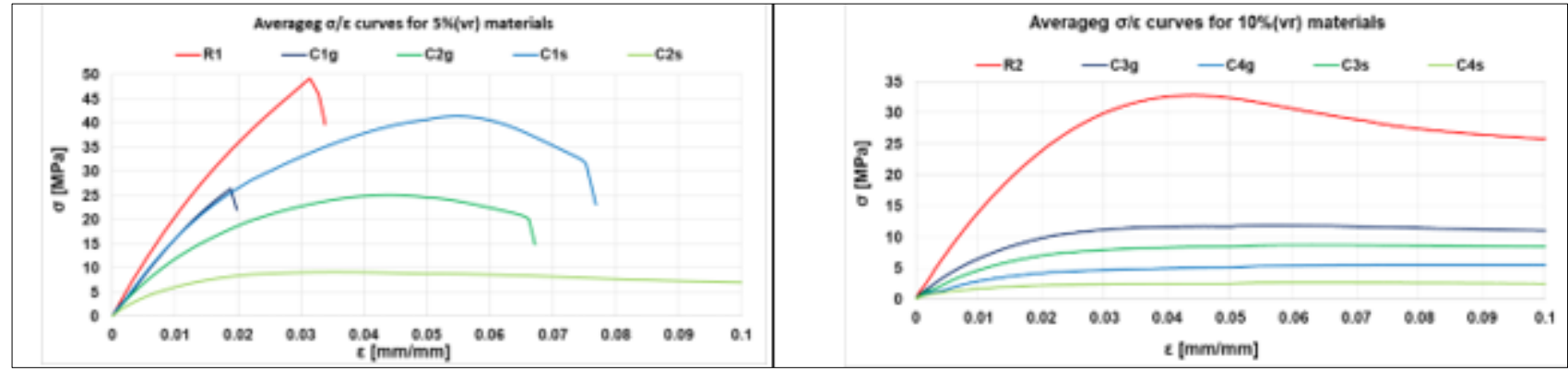

Figure 3. Averaged stress/strain curves for studied materials

The elastic moduli of studied materials are presented in Figure 4, once again compared with the reference materials (R1 and R2). It is obvious that the values of the elastic modulus decrease with the concentration of modifying solution into the epoxy matrix and, also, that the values of elastic modulus are higher for globally formed materials than the ones of separately formed materials. However, the values of elastic modulus of inorganic salts modified materials are lower than the ones of reference materials. 


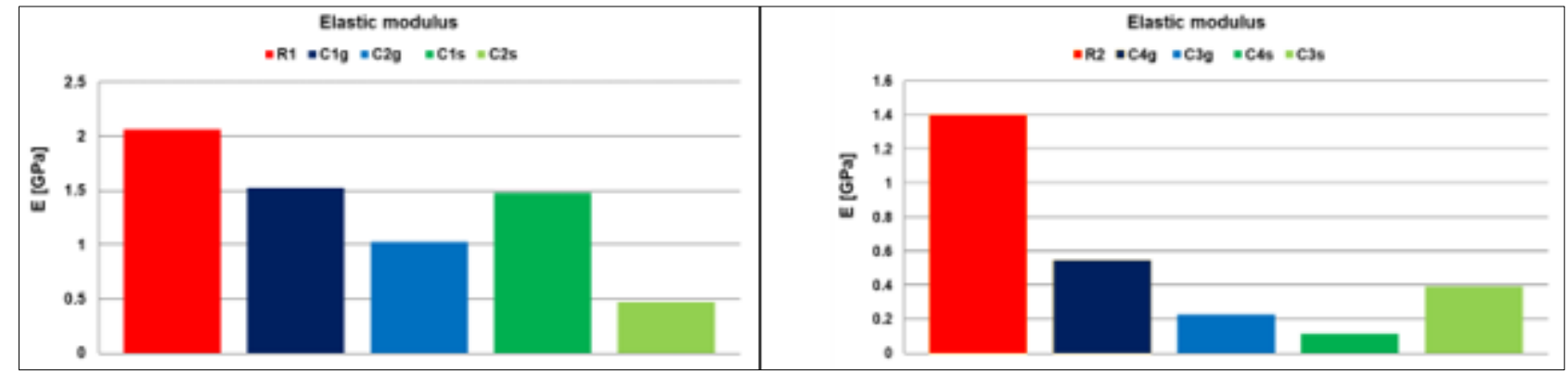

Figure 4. Elastic modulus of studied materials

Due to its time consuming feature the SEM analysis was done for the highest concentration materials - when the chemical interaction is more probable. In Figure 5 the SEM micrographs of C3g and C4g are showed. Due to the above listed observations, also the decision was to not investigate by SEM means the $\mathrm{C} 3 \mathrm{~s}$ and $\mathrm{C} 4 \mathrm{~s}$ materials. For the $\mathrm{C} 3 \mathrm{~g}$ material some sharp edged structures are observable while in the case of $\mathrm{C} 4 \mathrm{~g}$ material some globular structures are observable. The EDX analysis showed in Figure 6. All the elements of interest are present (according to the presented spectra) but Carbon that had been avoided from analysis in order to short it. The two spectra show uniform distributions for the investigated elements but they are not offering information about the structure of obtained structured. Also local (punctual) EDX analysis was performed but the results are not very significant. In fact, the SEM analysis was done on just one section of one sample and therefore is not entirely relevant but, at the beginning, it showed the existence of some agglomerations.

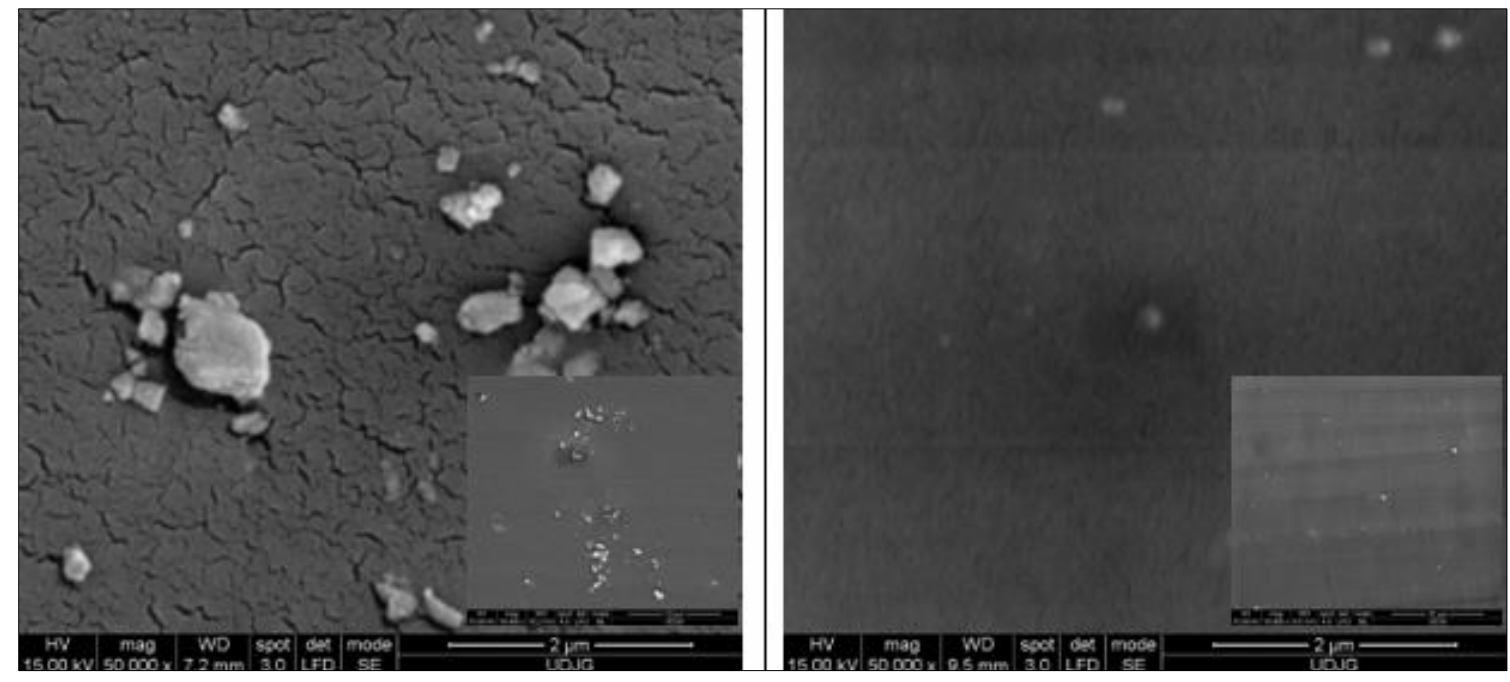

Figure 5. SEM micrographs of C3g (left) and C4g (right) materials 


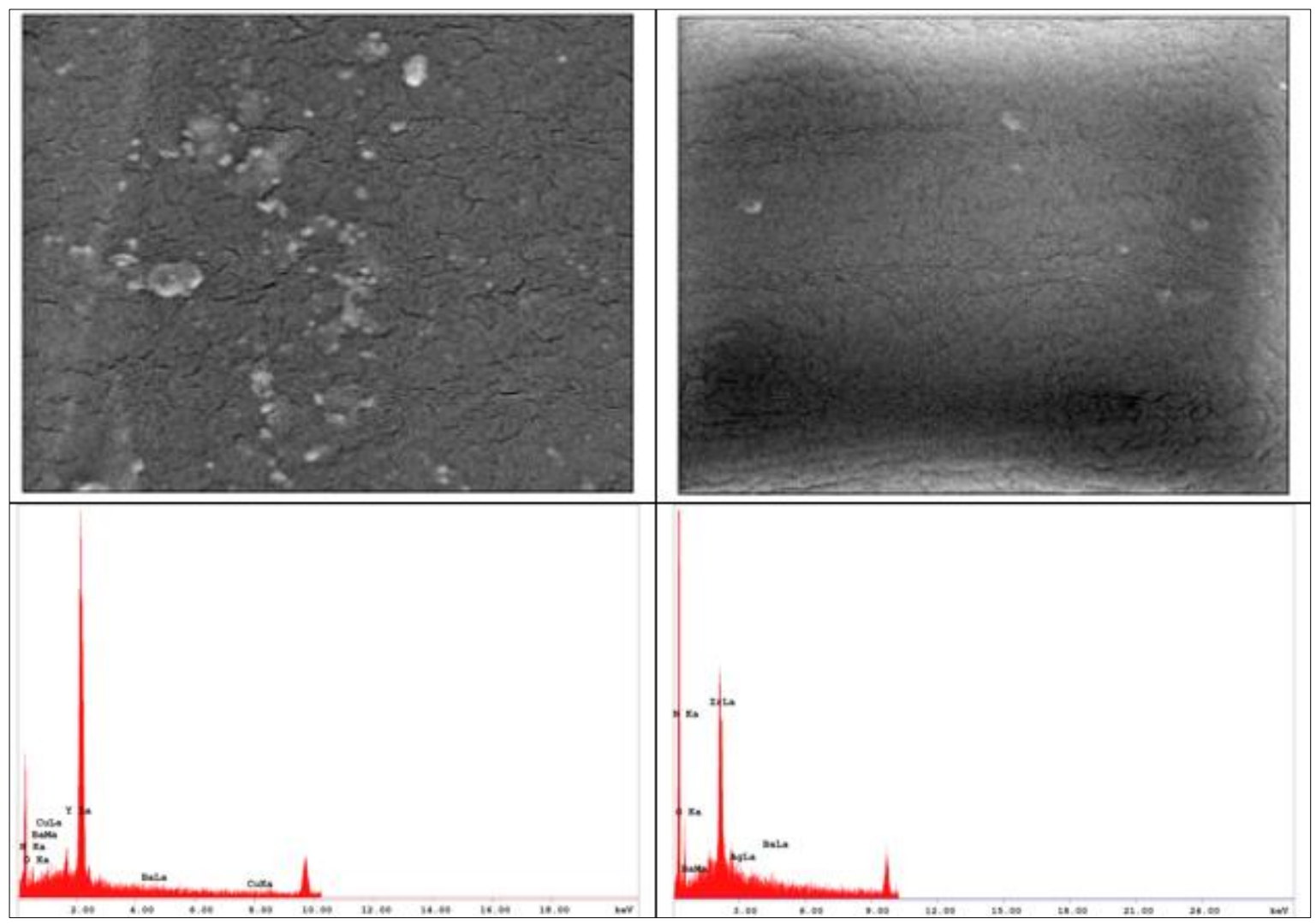

Figure 6. EDX analysis of $\mathrm{C} 3 \mathrm{~g}$ (left) and $\mathrm{C} 4 \mathrm{~g}$ (right) materials

\section{Conclusions}

Inorganic salts modified epoxy materials have been formed to verity the hypothesis of spontaneous nanostructuration of polymer. Each of the inorganic salts was solved in $50 \mathrm{~mL}$ of 1-methyl 2pyrrolidinone (NMP) and in order to stabilize the solutions in each one $5 \mathrm{~g}$ of polyvinylpyrrolidone have been added. For first type of materials Yttrium nitrate, Barium nitrate and Copper nitrate had been used while for the second type of materials Zirconium oxynitrate, Barium nitrate and Silver nitrate had been used.

The formation of materials followed two paths - one, named global, in which equal amounts of each salt were put together prior their amalgamation with epoxy resin and, the other one, named separate, when equal amount of each solution were mixed with one third of epoxy resin required amount.

Mechanical properties showed that the materials formed with Yttrium, Barium and, Copper are more stable (from the mechanical point of view) than the ones formed with Zirconium, Barium, and, Silver. The values of elastic modulus of inorganic salts modified epoxy are lower than the ones corresponding to PVP/NMP modified epoxy at the same amount of solution meaning that the presence of inorganic salts (or presence of aggregates) determines structural modifications (by blocking, for instance, the epoxy reticulation development during polymerization).

The SEM analysis, done on just one surface of a single sample of each material, revealed the existence of some structures (sharp edged for Yttrium materials and globular for Zirconium materials). This might be considered a proof regarding the nanostructuration of epoxy resin through some locally developed chemical reactions (especially in the case of Yttrium, Barium, Copper modified polymer). The SEM analysed surfaces were obtained by fracturing the samples so, there exists the possibility that the fracture have place exactly there because of the aggregates presence.

The EDX analyses, done on small areas of each material, revealed that all the elements were uniform distributed on these areas. A local EDX analysis could prove the validity of the initial hypothesis but it is very difficult because the results that have been obtained showed, for example, Yttrium concentrations of more than $50 \%$. 
The study has to be continued trying to find ways to stimulate the local chemical reactions. Also it is important to make an extensive EDX analysis in order to investigate the chemical constitution of aggregates. Of course, the EDX analysis has to be associated with SEM analysis performed in many sections of samples.

Acknowledgements. The work of Adrian Cîrciumaru and Vasile Bria was supported by the Project "EXPERT", Contract no. 14PFE/17.10.2018.

\section{References}

1.F.-L. JIN, X. LI, S.-J. PARK, Synthesis and application of epoxy resins: A review, Journal of Industrial and Engineering Chemistry, vol. 29, pp. 1-11, Sep. 2015.

2.M. KUBISZTAL, G. HANECZOK, A. CHROBAK, A. KUBIK, J. RASEK, Study of epoxy resin curing process by applying internal friction technique, Materials Science and Engineering: A, vol. 521522, pp. 283-286, Sep. 2009.

3.H. JIANG et al., Novel biobased epoxy resin thermosets derived from eugenol and vanillin, Polymer Degradation and Stability, vol. 160, pp. 45-52, Feb. 2019.

4.J. K. FINK, Epoxy Resins, in Reactive Polymers Fundamentals and Applications, Elsevier, 2013, pp. 95-153.

5.G. GIBSON, Epoxy Resins, in Brydson's Plastics Materials, Elsevier, 2017, pp. 773-797.

6.D. LAOUCHEDI, B. BEZZAZI, C. ARIBI, Elaboration and characterization of composite material based on epoxy resin and clay fillers, Journal of Applied Research and Technology, vol. 15, no. 2, pp. 190-204, Apr. 2017.

7.B. ELLIS, Ed., Chemistry and Technology of Epoxy Resins. Dordrecht: Springer Netherlands, 1993.

8.V. D. RAMOS, H. M. DA COSTA, V. L. P. SOARES, R. S. V. NASCIMENTO, Modification of epoxy resin: a comparison of different types of elastomer, Polymer Testing, vol. 24, no. 3, pp. 387-394, May 2005.

9.C. A. MAY, Ed., Epoxy resins: chemistry and technology, 2nd ed., rev. And expanded. New York: M. Dekker, 1988.

10.W. FERDOUS, A. MANALO, T. ARAVINTHAN, G. VAN ERP, Properties of epoxy polymer concrete matrix: Effect of resin-to-filler ratio and determination of optimal mix for composite railway sleepers, Construction and Building Materials, vol. 124, pp. 287-300, Oct. 2016.

11.J. C. J. BART, Additives in polymers: industrial analysis and applications. Chichester, West Sussex, England; Hoboken, NJ: John Wiley \& Sons, 2005.

12.K. D. JANSSON, C. P. ZAWODNY, T. P. WAMPLER, Determination of polymer additives using analytical pyrolysis, Journal of Analytical and Applied Pyrolysis, vol. 79, no. 1-2, pp. 353-361, May 2007.

13.S. AL-MALAIKA, F. AXTELL, R. ROTHON, M. GILBERT, Additives for Plastics, in Brydson's Plastics Materials, Elsevier, 2017, pp. 127-168.

14.V. AMBROGI, C. CARFAGNA, P. CERRUTI, V. MARTURANO, Additives in Polymers, in Modification of Polymer Properties, Elsevier, 2017, pp. 87-108.

15.E. A. COLEMAN, Plastics Additives, in Applied Plastics Engineering Handbook, Elsevier, 2017, pp. 489-500.

16.J. C. J. BART, Polymer additive analysis at the limits, Polymer Degradation and Stability, vol. 82, no. 2, pp. 197-205, Jan. 2003.

17.J. G. DROBNY, Additives, in Handbook of Thermoplastic Elastomers, Elsevier, 2014, pp. 17-32.

18.J.-M. LEE, Y.-D. JUN, D.-W. KIM, Y.-H. LEE, S.-G. OH, Effects of PVP on the formation of silverpolystyrene heterogeneous nanocomposite particles in novel preparation route involving polyol process: Molecular weight and concentration of PVP, Materials Chemistry and Physics, vol. 114, no. 2-3, pp. 549-555, Apr. 2009.

19.V. K. THAKUR M. K. THAKUR, Handbook of polymers for pharmaceutical technologies. Hoboken, New Jersey; Salem, Massachusetts: John Wiley \& Sons, Inc, 2015. 
20.R. AWASTHI, et al., Poly(vinylpyrrolidone), in Engineering of Biomaterials for Drug Delivery Systems, Elsevier, 2018, pp. 255-272.

21.P. A. WILLIAMS, Ed., Handbook of industrial water soluble polymers. Oxford; Ames, Iowa: Blackwell Pub, 2007.

22.V. BÜHLER, Polyvinylpyrrolidone excipients for pharmaceuticals: povidone, crospovidone, and copovidone. Berlin; New York: Springer, 2005.

23.T. KAVITHA, T. VASANTHA, P. VENKATESU, R. S. RAMA DEVI, T. HOFMAN, Thermophysical properties for the mixed solvents of $N$-methyl-2-pyrrolidone with some of the imidazolium-based ionic liquids, Journal of Molecular Liquids, vol. 198, pp. 11-20, Oct. 2014.

24.K. R. REDDY, D. B. K. KUMAR, G. S. RAO, P. B. S. SRI, C. RAMBABU, Vapor-liquid equilibria and excess molar volumes of $N$-methyl-2-pyrrolidone with 2-alkoxyethanols, Fluid Phase Equilibria, vol. 336, pp. 52-58, Dec. 2012.

25.H. WANG, K. XIE, L. WANG, Y. HAN, N-methyl-2-pyrrolidone as a solvent for the non-aqueous electrolyte of rechargeable Li-air batteries, Journal of Power Sources, vol. 219, pp. 263-271, Dec. 2012. 26.P. GNANAKUMARI, P. VENKATESU, K. R. MOHAN, M. V. P. RAO, D. H. L. PRASAD, Excess volumes and excess enthalpies of $\mathrm{N}$-methyl-2-pyrrolidone with branched alcohols, Fluid Phase Equilibria, vol. 252, no. 1-2, pp. 137-142, Mar. 2007.

27.H.-M. LI, S.-Y. YANG, J.-W. WANG, L.-S. LONG, R.-B. HUANG, L.-S. ZHENG, Coordination steric effect of $N, N$-dimethylformamide, $N, N$-dimethylacetamide and $N$-methyl-2-pyrrolidone on the assembly of coordination polymers, Polyhedron, vol. 29, no. 14, pp. 2851-2856, Sep. 2010.

28.C. MORENO-MARRODAN, F. LIGUORI, P. BARBARO, Sustainable processes for the catalytic synthesis of safer chemical substitutes of N-methyl-2-pyrrolidone, Molecular Catalysis, vol. 466, pp. 6069, Apr. 2019.

29.S. E. JASIM, M. A. JUSOH, M. HAFIZ, R. JOSE, Fabrication of Superconducting YBCO Nanoparticles by Electrospinning, Procedia Engineering, vol. 148, pp. 243-248, 2016.

30.X. LU, L. LI, W. ZHANG, C. WANG, Preparation and characterization of $\mathrm{Ag}_{2} \mathrm{~S}$ nanoparticles embedded in polymer fibre matrices by electrospinning, Nanotechnology, vol. 16, no. 10, pp. 22332237, Oct. 2005.

31.V. V. RODAEV, A. O. ZHIGACHEV, Y. I. GOLOVIN, Fabrication and characterization of electrospun $\mathrm{ZrO}_{2} / \mathrm{Al}_{2} \mathrm{O}_{3}$ nanofibers, Ceramics International, vol. 43, no. 17, pp. 16023-16026, Dec. 2017.

32.H. C. GUO, E. YE, Z. LI, M.-Y. HAN, X. J. LOH, Recent progress of atomic layer deposition on polymeric materials, Materials Science and Engineering: C, vol. 70, pp. 1182-1191, Jan. 2017.

33.M.-C. GOROVEI, M. BUNEA, A. CÎRCIUMARU, I.-G. BÎRSAN, Thermal analysis of polymer blends, Mater. Plast., 56(4), 2019, 680-687.

Manuscript received: 19.03 .2021 